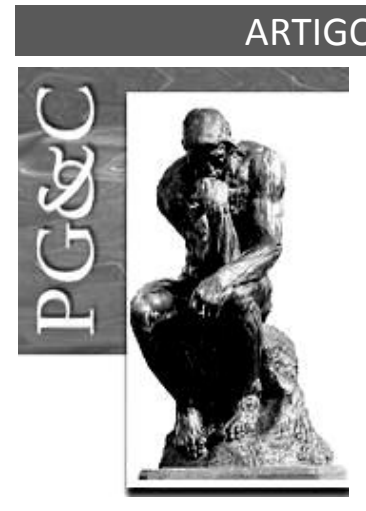

\title{
TECNOLOGIA E DESENVOLVIMENTO SOCIAL: UMA ABORDAGEM TEÓRICA
}

\author{
Vinicius Ferreira Baptista \\ Doutor em Políticas Públicas e Formação Humana pela Universidade do \\ Estado do Rio de Janeiro, Brasil. Professor da Universidade Federal Rural \\ do Rio de Janeiro, Brasil. \\ E-mail: viniciusferbap@ufrri.br
}

\begin{abstract}
Resumo
O presente texto discute elementos teóricos acerca de Tecnologia, especificamente em três vertentes: Tecnologia Aplicada, Tecnologia Social e Adequação Sociotécnica. A metodologia aplicada foi a de revisão bibliográfica com o objetivo de mapear uma visão objetiva sobre tecnologia e desenvolvimento social. Situa-se que a Tecnologia é capaz de produzir materialidade no desenvolvimento social, incluindo populações marginalizadas e permitindo melhora da qualidade de vida e promoção de oportunidades sociais. Neste sentido, temos um retrospecto das perspectivas da Tecnologia, desde a tecnologia apropriada, tecnologia social e adequação sóciotécnica, cada uma com um projeto de desenvolvimento. Entende-se que, para cada visão, existe um aspecto de desenvolvimento e que, notadamente, a Tecnologia Social e a Adequação Sociotécnica são as que apresentam vinculação mais próxima ao de desenvolvimento social atrelado à mudança de condições sociais.
\end{abstract}

Palavras-chave: Tecnologia. Desenvolvimento social. Tecnologia social. Adequação Sociotécnica.

\section{TECHNOLOGY AND SOCIAL DEVELOPMENT: A THEORETICAL APPROACH}

\begin{abstract}
The present text discusses theoretical elements about Technology, specifically in three aspects: Applied Technology, Social Technology and Sociotechnical Adequacy. The applied methodology was bibliographical revision with the objective to map an objective vision on technology and social development. We seek to situate that Technology is capable of producing materiality in social development, including marginalized populations and allowing improvement of the quality of life and promotion of social opportunities. In this sense, we make a retrospect of the technology perspectives, from the appropriate technology, social technology and socio-technical adequacy, each with a development project. We understand that, for each vision, there is an aspect of development and that, in particular, Social Technology and Sociotechnical Adequacy are the ones that present a closer link to that of social development linked to the change of social conditions.
\end{abstract}

Keywords: Technology. Social development. Social technology. Sociotechnical adequacy.

\section{INTRODUÇÃO}

Este ensaio vem discutir alguns aspectos sociais referentes à Tecnologia como proposta de desenvolvimento social. Primeiramente introduzimos elementos acerca de Tecnologia e as imbricações com o aspecto social. Em seguida apresentadas concepções de tecnologia em coadunação com as perspectivas de desenvolvimento social de cada uma. Por fim, não temos como objetivo esgotar o debate, porém levantar questões acerca do tema. Se a Tecnologia não pode ser dissociada de um aspecto propositivo, então pode-se questionar qual 
a sistemática que a encobre enquanto projeto político. Neste sentido, a Tecnologia Aplicada, a Tecnologia Social e a Adequação Sociotécnica se apresentam como possibilidades para pensar tal sistemática, ainda que com diferenças em objetivo, metodologia e resultados.

Se a Tecnologia não pode ser dissociada de um aspecto propositivo, então pode-se questionar qual a sistemática que a encobre enquanto projeto político. Neste sentido, a Tecnologia Aplicada, a Tecnologia Social e a Adequação Sociotécnica se apresentam como possibilidades para pensar tal sistemática. Principalmente acerca da questão do desenvolvimento: qual modelo de desenvolvimento se situa politicamente diante do contexto social observado? Se desenvolve para quem, por quem, com quem? O desenvolvimento é pensado de forma participativa?

Não pensamos a tecnologia como um processo em que há algo especificamente tangível. Observamos também a questão do conhecimento, da técnica e de sua criação e transmissão. Esta é a visão da Tecnologia que temos como ponto de partida: a que engloba conhecimentos, processos e métodos. Existem diversas concepções sobre a Tecnologia. Entretanto, neste trabalho, entendemos a tecnologia como um processo socialmente construído, não neutro e com propósitos bem definidos (ainda que não necessariamente claros à primeira vista), que iniciam desde a sua concepção à sua aplicação como processos interligados. As inovações sociais têm como saídas novas Instituições, novos movimentos sociais, novas práticas sociais, ou diferentes estruturas de trabalho colaborativo que têm um impacto no desenvolvimento social futuro e na presente estabilidade além dos "modismos" temporários

Assim, procuramos situar a Tecnologia na perspectiva do desenvolvimento. Situamos que a Tecnologia é capaz de produzir materialidade no desenvolvimento social, incluindo populações marginalizadas e permitindo melhora da qualidade de vida e promoção de oportunidades sociais (FREITAS; SEGATTO, 2014; GARCIA, 2014). Neste sentido, fazemos um retrospecto das perspectivas da Tecnologia, desde a tecnologia apropriada, tecnologia social e adequação sociotécnica, cada uma com um projeto de desenvolvimento. Esta compreensão permite argumentação sobre os impactos da tecnologia no desenvolvimento e promoção social.

\section{TECNOLOGIA: CONCEITOS INICIAIS}

Segundo a Lei no. 10.973/2004, que dispõe sobre incentivos à inovação e à pesquisa científica e tecnológica no ambiente produtivo, a Inovação compreende a "introdução de novidade ou aperfeiçoamento no ambiente produtivo ou social que resulte em novos produtos, processos ou serviços" (BRASIL, 2004). Neste sentido, a inovação não se refere unicamente às possibilidades tangíveis, no caso de produtos; não envolve necessariamente a existência de um produto concreto podendo referir-se também a processos e serviços. Há de se considerar que também envolve o ambiente social e mudanças na realidade do mesmo.

Por Tecnologia, entende-se "um conjunto de conhecimentos, processos e métodos empregados em diversos ramos", sendo uma "atividade socialmente organizada e baseada em planos e de caráter prático" (MAClEL; FERNANDES, 2011, p. 149). Não há como dissociar Tecnologia de Inovação quando consideramos processos sociais que as envolvem compreendendo-as isoladamente como aspectos não relacionados. Em dois sentidos: a Tecnologia pode ser utilizada como indutor à Inovação, ou seja, à inferência de novas possibilidades de retornos e atendimento às demandas e de novas formas de intervenção sobre a realidade local. Por outro lado, as estratégias de Inovação são imprescindíveis para a criação de novas Tecnologias ou de novos usos para a mesma, ou seja, a Tecnologia se reinventa pela Inovação de suas composições e de utilidade. 
A inovação tecnológica é fundamental para o desenvolvimento social e econômico e para o aumento do bem-estar da população, uma vez que é capaz de criar mecanismos que produzam impactos em termos como renda, empregos, conforto, atividades, técnicas, comunicação, dentre outros elementos que podem induzir condições melhores de vida (FREITAS; SEGATTO, 2014; GARCIA, 2014). O acompanhamento do processo de gênese de novas tecnologias contribui decisivamente para identificar as possibilidades de desenvolvimento e aumento do bem-estar, assim como "as ações necessárias para viabilizá-lo" (ARAKAKI; PRIANTE FILHO; SAMPAIO NETO; LUCONI; PAESE, 2012, p. 62). Por conta disso, nos interessa situar como a Tecnologia é concebida e interpretada no que toca à sua elaboração, aplicação e replicação e de que forma a mesma é percebida como indutora de mudanças na realidade social por aqueles que a utilizam.

O trabalho de Pinch e Bijker, datado de 1984, é um dos precursores das pesquisas em torno da construção social da tecnologia (Social Construction of Technology - SCOT, sua sigla em inglês). O artigo "Social Construction of Facts and Artefacts" teve como objetivo demonstrar que "o estudo da ciência e o estudo da tecnologia deveriam, e efetivamente podem beneficiar-se a partir de cada um" (PINCH; BJIKER, 1984, p. 400). Serafim e Dias (2010) argumentam que este trabalho procurou fugir das explicações convencionais, essencialmente lineares a respeito da tecnologia. Para os autores, há a concordância de que o conhecimento é uma construção social e que considerado desta forma, entende-se que "não há nada epistemologicamente especial sobre a natureza do conhecimento científico, por ser uma dentre várias séries de culturas de conhecimento" (PINCH; BJIKER, 1984, p. 402).

O contexto da inovação tecnológica considerado pelos autores é de que a mesma acompanha o processo histórico de sua construção, sempre atrelada a propósitos, nem sempre claros. A Ciência e a Tecnologia "são ambas culturas socialmente construídas e trazem para todos os recursos culturais que sejam apropriados para os propósitos à mão" (PINCH; BJIKER, 1984, p. 404). Isso significa que a ciência e tecnologia têm propósitos à mão. Este pode ser um primeiro argumento de que não há um determinismo sobre a tecnologia, por a mesma já ser imbuída em contextos que a moldam observando determinados fins.

Por outro lado, essa posição ainda é incipiente, uma vez que a própria tecnologia em si, muitas vezes, não é objeto de discussão. Na inovação tecnológica, o espaço se abre para avaliações econômicas e até mesmo o próprio processo de inovação em si, exceto a da própria tecnologia. É aqui que os autores centram sua argumentação: observar a tecnologia a partir de si, abrindo sua caixa preta (black box).

Entretanto, chamar a Tecnologia de black box contém um perigo metodológico. Partir da ideia da mesma como tal, é conceber a tecnologia como um processo em que se sabe que algo "existe", mas cujas bases se desconhece. A Tecnologia não pode partir desse processo para seu conhecimento - o que traz um descuido inicial de Pinch e Bijker no que toca à SCOT. A Tecnologia não apresenta elementos obscuros que existem, mas que não se sabe como funcionam ou como influenciam o processo. Estes elementos existem e cabem ao pesquisador proceder à sua descoberta.

A ideia de que a tecnologia é ampla e socialmente construída é percebida como um entendimento geral, para Winner (1993). O autor situa que a tecnologia pode ser concebida em diversos lugares e não unicamente nos laboratórios, fábricas e indústrias. Da mesma forma, a tecnologia possui materialidade histórica, seguindo o fluxo das disputas políticas, produtivas e nos contextos socioeconômicos das épocas.

Ainda que não façam menção à concepção da não-neutralidade e do processo de construção que oscila em volta da inovação, Moreira e Queiroz (2007, p. 6) sublinham a questão do "social" que a circunda, impactando reciprocamente os processos de inovação e da tecnologia. Interessa destacar que "existe uma interação contínua e dinâmica entre novas ideias, práticas e produtos, de um lado, e a estrutura e a função social, de outro". Ou como os

Perspectivas em Gestão \& Conhecimento, João Pessoa, v. 9, n. 1, p. 4-23, jan./abr. 2019. 
próprios autores contextualizam, "as inovações podem criar mudança social", a qual "pode trazer inovações adicionais que podem reagir sobre as estruturas e/ou funções alteradas que as fizeram existir ou influenciar outros aspectos da organização (MOREIRA, QUEIROZ, 2007, p. $6)$.

Como exemplificado por Maciel (2001 apud ANDRADE, 2005), o que se pensa como possibilidade de uma construção da inovação tem como propósito basilar a articulação entre tecnologia, economia e vida social, diferenciadamente e de modo aberto, distanciando a lógica tradicional em que a inovação tecnológica é relacionada unicamente, ou majoritariamente, ao setor produtivo.

A disputa de grupos no entorno da tecnologia é potencial para a construção da mesma. Isso foi indicado por Pinch e Bijker (1984), mas não foi desenvolvido plenamente. Mas interessa situar que "grupos potenciais podem confrontar barreiras significantes para a organização e participação" (KLEIN; KLEINMAN, 2002, p. 37). Aqui, para os autores, seria uma oportunidade ímpar de discorrer sobre a potencialidade de consumidores, indústria, fabricantes etc., em torno da tecnologia. Serafim e Dias (2010) já ponderavam que a Tecnologia é um objeto social e político. Já a Política é uma tecnologia de organização social, portanto, as duas estão intrinsecamente interconectadas

Como pondera Andrade (2005, p. 154) "a inovação socioeconômica é o vetor de transformação tecnológica, e não o contrário". Por outro lado, relembrando a discussão de Latour (2000), o contexto social está intrinsecamente associado ao modelo de desenvolvimento vigente, em que os agentes inovadores controlam na tentativa de reduzir a imprevisibilidade e instabilidade. Neste momento, um argumento de Maciel (1996) é bastante oportuno de ser considerado onde, para a autora, o sentido de inovação tende a ser colonizado pela concepção dominante de desenvolvimento, o que retira desse sentido a incerteza e a experimentação constante. E tal perspectiva depende das concepções de tecnologia e suas aplicações.

\section{METODOLOGIA}

Este ensaio vem discutir alguns aspectos sociais referentes à Tecnologia como proposta de desenvolvimento. Quanto ao método e à forma de abordar o problema optou-se pela pesquisa qualitativa (RICHARDSON, PERES, WANDERLEY, PERES, 2007). Quanto aos procedimentos adotados na coleta de dados tem-se a pesquisa bibliográfica buscando conhecer e analisar as contribuições políticas e científicas (GIL, 2007). O principal aporte teórico se apoia no contexto acerca das tecnologias, notadamente sobre Tecnologia Aplicada e Tecnologia Social, as obras de Singer, (2002), Dagnino, Brandão e Novaes (2004) e FBB (2012), Tenório (1998) e Rodrigues e Barbieri (2008).

Procuramos situar a Tecnologia na perspectiva do desenvolvimento. Situamos que a Tecnologia é capaz de produzir materialidade no desenvolvimento social, incluindo populações marginalizadas e permitindo melhora da qualidade de vida e promoção de oportunidades sociais. Neste sentido, fazemos um retrospecto das perspectivas da Tecnologia, desde a tecnologia apropriada, tecnologia social e adequação sóciotécnica, cada uma com um projeto de desenvolvimento. Esta compreensão permite argumentação sobre os impactos da tecnologia no desenvolvimento e promoção social.

\section{CONCEPÇÕES DE TECNOLOGIA E APLICAÇÕES}

Entre os conceitos mais comuns referentes à Tecnologia está a Tecnologia Aplicada (TA), cuja origem remete ao movimento durante as décadas de 1960 e 1970 em torno da "reação dos padrões de crescimento econômico do pós-guerra tanto nos países denominados 
Primeiro Mundo nessa época, quanto nos denominados Terceiro Mundo" (RODRIGUES, BARBIERI, 2008, p. 1071). Já Novaes indica que suas raízes remetem à Índia do final do século 19 , onde suas bases se voltavam à "reabilitação e o desenvolvimento das tecnologias tradicionais, praticadas nas suas aldeias, como estratégia de luta contra o domínio britânico" (NOVAES, 2010, p. 155).

O berço da TA remonta à Índia do final do século XIX. Dagnino, Brandão e Novaes (2004) ponderam que os formuladores daquela sociedade tinham como objetivo reabilitar o desenvolvimento das tecnologias tradicionais. Ghandi iniciaria um processo entre 1924 e 1927, com vistas à popularização da fiação manual.

O processo tinha como base significativa a "produção pelas massas, não produção em massa" - como preconizado pelo próprio Ghandi (DAGNINO; BRANDÃO, NOVAES, 2004). Ghandi desenvolveria uma política científica e tecnológica. Ainda que não institucionalizada, tal política insistiria na proteção da produção local dos artefatos das aldeias. Isso implicaria o melhoramento das técnicas locais, adaptando-as às necessidades materiais e às demandas técnicas locais, transformando a sociedade hindu de dentro para fora. No entanto, a TA era considerada como "sinônimo de tecnologia atrasada, superada pelos avanços sistematicamente proporcionados pela incorporação de novos conhecimentos gerados pelas atividades de P\&D [Pesquisa e Desenvolvimento]" (RODRIGUES, BARBIERI, 2010, p. 1073).

É inevitável, nesta questão, associar tal sistema à proposta SCOT no que toca à escolha técnica, onde Ghandi orienta processos e metodologias ao conhecimento desenvolvimento localmente, em um claro processo de flexibilidade interpretativa acerca das demandas locais, os grupos ali presentes, tendo em mente as normas e valores construídos e aceitos coletivamente. Em determinada perspectiva analítica, trata-se de um processo de empoderamento. Um processo desenvolvedor de autonomia e criticidade das ações necessárias a serem pensadas, elaboradas e interpostas coletiva e de modo participativo. As relações de dependência e poder, neste contexto, se diluem.

Tal pensamento da TA como "atraso" deve ser analisada com cuidado. Se a TA vem a, de certa maneira, substituir tecnologias convencionais, mais caras e não necessariamente "aplicáveis" a determinadas conjunturas, isso significa que não se torna imprescindível o uso daquelas tecnologias e, com isso, a relação de dependência é rompida de alguma forma. Se uma relação de dependência é rompida, consequentemente, a influência de certos atores, detentores da capacidade de influenciar ou que possuam relação com a mesma, vai se diminuindo em alcance e potência. Tal perspectiva é negativa para aqueles que exercem relações de poder e que possuem vantagens. $E$ uma das ações é desconstruir o processo emancipatório que a TA venha a desenvolver. E determinar a TA como "atraso", "incapaz", "que não incorpora os avanços tecnológicos" - estes últimos, sempre mais caros e inacessíveis, é um dos passos para tal desconstrução.

Neste ponto situa-se o debate sobre a função social da Tecnologia, ou melhor, a contribuição da Tecnologia nas questões e demandas levantadas pela sociedade. Aqui há o entendimento de que a Tecnologia Convencional (TC), utilitária e empregada em contextos mercadológicos, não é apropriada à conjuntura de países periféricos, uma vez que nas relações entre a tecnologia e a sociedade, a primeira vislumbrando sobre o âmbito privado, não se parelha às realidades da segunda que, vislumbrada sobre o âmbito público, tem outra orientação.

O contraponto da Tecnologia Aplicada aparece no fato de que a mesma teria sido pautada pela possibilidade de neutralidade da ciência e do determinismo tecnológico, e por conta disso apresentava uma postura "defensiva, adaptativa e não questionadora das estruturas de poder dominantes no plano internacional e local" (NOVAES, 2010, p. 164). Por outro lado, "o movimento da tecnologia apropriada contribuiu para o debate a respeito dos 
projetos de desenvolvimento nacionais e, para muitos países, para a própria luta de libertação nacional" (RODRIGUES; BARBIERI, 2008, pp. 1072-1073).

Um dos argumentos não trazidos aqui e que seria essencial para análise da TA é a questão das correlações de poder, que acaba mascarada pelo entendimento de uma pseudoneutralidade da tecnologia, o que não há. A tecnologia tem propósito e possui atores e grupos envolvidos na sua construção. Ela é pensada visualizando uma possibilidade concreta. Se se pensa a TA como uma apropriação replicada (então trata-se de replicação) acaba-se por se desconectá-la dos seus processos fundadores e, portanto, não se questiona os mesmos, assim como as estruturas dominantes. A tecnologia não deve ser pensada como replicação, mas como um processo a ser construído socialmente.

Havia o entendimento de que a TA era voltada a um propósito amplo, de resolução de problemas sociais, de questões referentes ao desenvolvimento, à qualidade de vida, às perspectivas de mudanças sobre a realidade social. A TC visualizava o mercado, o lucro, a evolução tecnológica e sua replicação, a diminuição do esforço manual, a eliminação do fator humano (quando falamos dos meios de produção e da indústria, ou seja, eram expressões antagônicas.

Ainda que com esses aspectos "positivos" nas concepções da TA, existiram fortes críticas em relação à sua capacidade. Dagnino, Brandão e Novaes (2004, p. 25) situam que boa parte das críticas à TA era fundamentada na "neutralidade da ciência e do determinismo tecnológico". Tais críticas pautaram a TA como uma "ridícula volta ao passado". Lembrando em certa medida a metáfora de Peter Pan sobre a tecnologia no início do presente capítulo, predominava à época - e ainda se predomina no discurso deste século XXI - a tecnologia como livre de valores, neutra, independente e fora dos contextos político, econômico, social, cultural, tecnológico etc., assim como seguindo um processo evolutivo aparentemente linear.

Não há como desvincular a desqualificação da TA da visão linear e neutra sobre a tecnologia. De acordo com essa visão, a tecnologia não é um resultado ou, ao menos, um processo afetado pelo contexto histórico, ou seja, não tem materialidade histórica pois, ela se pautaria por um processo evolutivo reducionista sobre sua própria funcionalidade. Neste sentido, não haveria uma tecnologia que pudesse ser apropriada por um grupo ou ser criada especificamente para um grupo. Não caberia à tecnologia o papel de intervir sobre a realidade social, dado que ela seria neutra, independente dos atores nas arenas políticas e dos interesses mostrados (ou não) em jogo.

Caberia aqui indagar até que ponto tal desqualificação sobre a TA foi, em certa medida, calculada propositadamente, uma vez que se tratava de um processo não somente no campo tecnológico, mas também nos campos político, social, econômico, cultural, ambiental etc. que, se não reorganizasse as forças políticas e produtivas no contexto situado, ao menos produziria efeitos de questionamento, conhecimento e apropriação da realidade local. Seria a TA uma sugestão a ser considerada enquanto proposta política? A reorganização da estrutura social, das relações políticas e forças produtivas trazem um forte componente político que poderia ser analisado.

Há de se ter em mente que a evolução da TA segue, paralelamente, o fluxo ascendente da proliferação das ideias de Bem-Estar Social, largamente ampliado pelos países desenvolvidos ao longo das décadas de 1960 e 1970. Com o intuito de oferecer propostas que visassem dignidade e condições mínimas para a existência humana, não há como desconsiderar este ponto na evolução da TA.

Por outro lado, ao passo em que crises fiscais do Estado são, preliminarmente, indicativos e, posteriormente, considerados como medidas de salvaguarda para a reorganização do papel do Estado no que toca às políticas neoliberais e à instituição de um novo modelo da organização e ação estatal, entende-se a perda da força do movimento da TA. Afinal, com o estreitamento das relações entre o público e o privado, a redução dos 
investimentos no âmbito social, o avanço tecnológico privilegiando a minimização do esforço humano e a ênfase no capital intelectual, a diminuição do emprego e da deterioração dos vínculos produtivos, o espaço para a TA se reduziria.

A tecnologia, neste caso, era apenas para replicação do que era concebido pelas matrizes e, unicamente para fins da produção. Não se tratava de um processo de intervenção social. Tratava-se de realização de investimentos em Pesquisa e Desenvolvimento (P\&D) a fim de conceber novas técnicas e tecnologias a serem replicadas para a produção. Não se tinha um fim voltado às questões locais. Por outro lado, esse mesmo cenário, que abafou a existência da TA, serviu de críticas para a formulação de um novo entendimento que viria a partir da Tecnologia Social (TS), aproveitando as bases da primeira.

É neste contexto em que os conceitos em torno da Tecnologia Social (TS) vão ganhando mais força. Aqui, a inovação "não pode ser pensada em algo feito num lugar e aplicado em outro, mas como um processo desenvolvido no lugar onde essa tecnologia vai ser utilizada, pelos atores que irão utiliza-las" (DAGNINO; BRANDÃO; NOVAES, 2004, p. 56-57). Enquanto que a Tecnologia Aplicada focalizava mudanças adaptativas em torno dos produtos, a Tecnologia Social foca nas mudanças transformadoras em torno dos processos.

\section{A TECNOLOGIA SOCIAL}

A tecnologia, para a teoria da inovação "só se constitui como tal quando tiver lugar um processo de inovação", do qual insurja um conhecimento criado que objetive "atender aos problemas que enfrenta a organização ou grupo de atores envolvidos". A ideia da TS possui esse entendimento exposto (DAGNINO; BRANDÃO; NOVAES, 2004, p. 33).

O processo de difusão ou transferência de tecnologia previsto em uma dada empresa pela teoria de inovação como um processo de inovação possuidor de características particulares, a TS observa esse ponto como "reaplicação", ou seja, "um processo específico com aspectos distintos" (DAGNINO; BRANDÃO; NOVAES, 2004, p. 33), diferentemente da mera "replicação", ou seja, uma dada tecnologia "pronta" que é transferida para ser aplicada nos mesmos "moldes" em que foi concebida, sem ter nenhuma adaptação quanto ao local ou à forma como seria utilizada.

Ressalte-se que a Tecnologia Social se volta prioritariamente para a emancipação dos atores envolvidos, tendo centralidade na condução do processo os próprios produtores e usuários dessas tecnologias, implicando, para Rodrigues e Barbieri (2008, p. 1075), "a construção de soluções de modo coletivo pelos que irão se beneficiar dessas soluções e que atuam com autonomia, ou seja, não são apenas usuários de soluções importadas ou produzidas por equipes especialistas". Essa emancipação está associada diretamente com as escolhas técnicas, o processo produtivo, a correlação entre demandas, necessidades, expectativas e tecnologia, assim como na transferência de tecnologia e conhecimento.

Essa concepção pensada à TS teria em mente um ajuste entre a "demanda e a oferta", não nas definições "duras" pautadas pela teoria da inovação, mas plástica, considerando as demandas envolvidas e a capacidade ofertada, configurando um processo levado a cabo coletivamente "pelos atores interessados na construção daquele cenário desejável" (DAGNINO; BRANDÃO; NOVAES, 2004, p. 34). A TS aqui, acaba por se aproximar da "inovação social".

Aqui tem-se mais uma diferença entre a Tecnologia Aplicada e a Tecnologia Social: enquanto que a primeira entende a reprodução de tecnologias como base do processo produtivo; a segunda se destaca pela reconstrução do processo produtivo em si, com novas formas de apropriação, primeiramente da tecnologia, em segundo das forças produtivas e do modo de produção e, em terceiro, da organização social e política do sistema produtivo. Este último, o mais difícil de ser construído, uma vez que está em forte combate com o atual

Perspectivas em Gestão \& Conhecimento, João Pessoa, v. 9, n. 1, p. 4-23, jan./abr. 2019. 
sistema produtivo capitalista. Por outro lado, a tentativa em si de reorganizar o processo já é um indicativo de que não há uma única possibilidade de organização social e produtiva que seja proveitosa e que traga benefícios para seus associados. O Capitalismo, ou melhor, a forma capitalista de organização e produção não é mais o único caminho a seguir.

Por outro lado, a forma capitalista de organização e produção ainda é o preponderante no âmbito dos modelos de negócios. O fundamental aqui é trazer luz sobre as novas formas novas no sentido de proliferação e conhecimento como modelo válido a ser seguido - de organização e produção que invistam sobre as necessidades e demandas locais a partir do desenvolvimento local com apropriação e não expropriação e exploração como vias de regra. A apropriação deve ser pela localidade e por aqueles demandantes de mudanças sociais do local.

Nessas relações, para a proposição de um sistema nacional de inovação, o Estado tem papel central, tanto como indutor mas, notadamente, como mediador nas disputas que ocorrem naturalmente em qualquer ambiente que envolva grupos sociais distintos. A inovação social requer comprometimento de novas tecnologias, processos, métodos e técnicas que sejam voltadas ao contexto socioeconômico e político-institucional dos grupos sociais afetados por qualquer problema que necessite de intervenção ou mudança de status quo. 0 âmbito do mercado, por si só, não é capaz de absorver as demandas latentes e produzir e/ou atender especificamente à tais grupos. Por outro lado, o Estado, por si só, também não é capaz de fazer o mesmo. Assim como, os próprios grupos, sozinhos, são incapazes de induzir mudanças. Por conta disso, a formação de redes é fundamental à reorganização de interesses, demandas, conflitos e disputas para a proposição de medidas que visem à tais grupos, fortalecendo sua posição enquanto grupo em si.

Neste contexto, o Estado tem papel fundamental, enquanto ator social na conjuntura da construção social, principalmente na questão da estrutura tecnológica e contexto sociocultural e político - via suas políticas científicas e tecnológicas e de apoio às alternativas locais de desenvolvimento socioeconômico - no fechamento e estabilização de processos consensuais de que determinadas alternativas produtivas são válidas de apoio estatal, societal e do mercado para mudanças sociais efetivas e de protagonismo social de grupos da sociedade.

O arranjo pensado no conceito de inovação se parelha ao de sistema. Tendo o sistema como um arranjo a ser construído via ações coordenadas e planejadas, que pretenda "alavancar uma incipiente teia de atores ainda incapaz de gerar fortes sinais de relevância", e que venha a promover o "estabelecimento de relações virtuosas entre pesquisa e produção e um tipo particular de inovação" - a social, que "tem por objetivo o aumento da efetividade dos processos, serviços e produtos relacionados à satisfação das necessidades sociais" (DAGNINO, BRANDÃO; NOVAES; 2004, p. 35).

Sempre que se discute a inovação social e a questão dos sistemas, consecutivamente se remete à construção de relações virtuosas. Compreendendo o sistema político como um conjunto sistêmico em que se processam inputs, ou seja, as demandas visíveis e invisíveis, os apoios positivos ou negativos, por dentro de um subsistema político que contém suas próprias demandas e apoios, os withinputs (demandas dentro do sistema político), gerando decisões, propostas e políticas, os outputs - as relações intrínsecas ao sistema sempre são permeadas de disputas, conflitos, interesses, barganhas, conluios mas, também de negociações (RUA, 2009).

Estas negociações é que podem pautar uma forma diferente no que toca à construção de relações virtuosas e não viciosas entre pesquisa, produção e inovação. A formação de redes e o fortalecimento de atores antes renegados, muitas das vezes invisíveis ao subsistema político em si, perpassam as relações virtuosas. Elas ganham esta característica pela forma como pensam, propõem, implementam, monitoram e avaliam medidas de intervenção social, construídas participativamente entre os atores, com os atores, pelos atores e para os atores.

Perspectivas em Gestão \& Conhecimento, João Pessoa, v. 9, n. 1, p. 4-23, jan./abr. 2019. 
Elas são virtuosas por permitirem e incentivarem a emancipação e fortalecimento do poder de atores antes renegados aos processos de negociação.

Trata-se de um processo diferente de quando as relações são quebradas, desconstruídas, formadas pelos interesses de uns sobrepostos aos de outros, prevalecendo decisões pautadas por grupos mais influentes e que detém a tomada de decisão. As relações aqui são viciosas, por não serem medidas de intervenção que venham a modificar a realidade social, porque não são construídas visando os atores e grupos sociais interessados na mudança. Aqui, a inovação pode existir, mas que não se relaciona ao social.

Os elementos fundamentais da Tecnologia Social envolvem a concepção da tecnologia como desenvolvida e praticada com a população e apropriada por ela, ensejando "a ideia de participação ativa das pessoas, grupos e comunidades afetados pelas tecnologias" (RODRIGUES; BARBIERI, 2008, p. 1077). Por conta disso, uma das definições mais comuns da TS compreende que esta pode aliar saber popular, organização social e conhecimento técnicocientifico que sejam efetivas e reaplicáveis, propiciando desenvolvimento social em escala (FBB, 2013). A Tecnologia Social necessita que essas tecnologias "precisam garantir que sejam apropriadas para a comunidade, gerando mudanças de comportamentos, atitudes e práticas que proporcionem transformações sociais" (RODRIGUES; BARBIERI, 2008, p. 1077).

\section{TECNOLOGIA, INOVAÇÃO E ORGANIZAÇÕES}

Neste ponto, convém trazer o conceito de organização. A grosso modo, uma organização compreenderia metas, objetivos e uma estrutura organizativa, que visa o atendimento das necessidades e ou objetivos de um grupo. Já Caravantes, Panno e Kloeckner (2005, p. 43) apresentam o conceito de organização elaborado por Peter Drucker como "um grupo humano, composto por especialistas que trabalham em conjunto em uma atividade comum". O conceito de organização acima exposto é resumido e paralelamente traz a essência de uma organização: um esforço conjunto objetivando uma meta. Toda organização possui uma meta ou objetivo(s). São estes que as movem. E estas definem, em certa medida, o caráter da organização. Ao se pensar em inovação no ambiente organizacional, no sentido de investimento de tempo, energia, recursos, criatividade etc., um dos primeiros pensamentos envolvidos se refere à própria inovação em si ou no processo inovativo empreendido. Isso significaria duas possibilidades: ou se parte da concepção de uma inovação ("o que se quer inovar?", "O que trazer com a inovação?", por exemplo); ou, em uma segunda perspectiva, se parte da concepção de se inovar em algum processo produtivo ou processualidade em etapas da produção ("inovar em metodologias, técnicas, processos?").

Oliveira (2013, p. 19) pondera que "as organizações devem estar preparadas para inovar não só nos produtos e serviços, mas, complementarmente, no modelo de negócios". Isso corrobora a ideia de que inovação não está diretamente associada às formas tangíveis e facilmente observáveis, mas que também está diretamente associada às formas intangíveis, por exemplo às novas formas de gestão, como introduzir missão, visão, buscar novos parceiros estratégicos, formular diretrizes de atuação interna e externa ou diferentes formas de captar recursos para a viabilidade do empreendimento em si.

Por conta disso, a estrutura organizacional tem uma forte associação com qualquer projeto a ser desenvolvido dentro de uma organização, uma vez que a estrutura "pode favorecer as inter-relações entre as competências dos administradores, as culturas e os incentivos oferecidos pelas empresas" (FIGLIOLI, 2013, p. 81). Isso significa que tal estrutura aponta para uma composição que torna mais efetiva "a capacidade de uma escolha sensata dentre as alternativas que se apresentam para a organização em termos de inovação tecnológica" (2013, p. 81). Aqui percebemos o caráter social da tecnologia. 
Neste contexto, as organizações não são agentes passivos. Pelo contrário, são compostas por pessoas que, a priori, possuem objetivos em comum em torno de um projeto mais amplo - aqui, voltamos a pensar exclusivamente no âmbito das cooperativas. Figlioli (2013) destaca quatro elementos que têm relação direta com a capacidade de inovação em uma organização: 1) a Liderança e a Organização; 2) a Cultura e os Valores; 3) as Pessoas e as Capacidades; e, por fim, 4) os Processos e as Ferramentas.

A tecnologia e a inovação dentro das organizações, seja elas privadas ou públicas, ou de natureza monetária ou não monetária, os processos que a envolvem necessitam de adaptação ou mudanças dentro das organizações. O primeiro elemento - Liderança e Organização, "exige que líderes das empresas se alinhem em torno de uma visão comum da inovação de modo a favorecer a cultura e os valores da empresa". A autora propõe a centralização de decisões quanto à inovação, a criação de infraestrutura que possibilite pesquisa e desenvolvimento $P \& D$, além de propiciar melhores condições para interação (FIGLIOLI, 2013, p. 94).

O segundo elemento - Cultura e Valores, tem como objetivo a construção de uma cultura aberta e colaborativa, fornecendo bases para “que o diálogo com o 'sistema' existente dentro da empresa reflita em mudanças na cultura organizacional, ou seja, em suas normas, valores e princípios, visando à modificação dos rituais diários das empresas (FIGLIOLI, 2013, p. 94).

Já o terceiro elemento - Pessoas e Capacidades, "envolve o uso de meios para os incentivos à criação de capacidades de inovações por meio de uma abordagem disciplinada para a criação de inovações dentro da empresa". Significa capacitar pessoas para que as mesmas compreendam que podem inovar, "reforçando a interação com os valores da empresa para que a inovação seja incentivada em todas as esferas da organização" (FIGLIOLI, 2013, p. 94-95).

Por fim, o quarto elemento - Processos e Ferramentas, "é a chave para a estruturação dessa rede de elementos", tanto ideias, quanto pessoas capacitadas para a inovação e mudanças organizacionais. A autora aqui defende uma abordagem mais "mecânica", no sentido de que "é preciso transformar a ideia em realidade por meio de um conhecimento ferramental da empresa" (FIGLIOLI, 2013, p. 95).

Dentro de uma organização é preciso ter sinergia e entendimento mútuo de que os processos inovativos e inovadores são capazes de trazer valor à organização. Valor nos mais amplos sentidos: organizacionais, sociais, econômicos, ambientais, políticos etc. $O$ fato é que precisa existir um apoio dentro da organização - neste ponto a questão da Liderança é preponderante. $\mathrm{O}$ apoio deve vir não somente daqueles que ocupam um cargo de liderança, mas, sobretudo, daqueles que exercem algum tipo de liderança informal dentro da mesma. Deve ser um processo construído socialmente com benefício a todos.

Inevitavelmente, neste processo de difusão da importância da inovação perpassam a cultura organizacional e os valores da organização. Todo processo que envolva mudança social e tecnológica necessita ser: 1) compreendido; 2) acordado e consensuado; 3) aceito; 4) difundido e executado. Uma boa comunicação que permita reconhecimento e identificação nessa proposta como indicativo de mudanças que tragam efeitos positivos é essencial para angariar apoio e transformar a organização de dentro para fora. Os processos não devem ser percebidos como executáveis autoritariamente ou hieraquicamente (ainda que em alguns momentos, a tomada de decisão venha a ficar a cargo daqueles que exerçam cargos de liderança); pelo contrário, deve-se pensar a inovação no sentido aberto, principalmente se estivermos com o objetivo em mente de empreender inovações sociais.

Referente às pessoas e às capacidades e a conjuntura de inovação, trata-se de processos conectados e não difusos. A inovação passa pelas pessoas. Não são as máquinas que pensam a inovação; também não são elas que interpretam demandas, assim como visualizam

Perspectivas em Gestão \& Conhecimento, João Pessoa, v. 9, n. 1, p. 4-23, jan./abr. 2019. 
oportunidades e janelas; por fim, não são máquinas que executam processos de inovação. São processos que passam pelas pessoas. E se as mesmas não entenderem o sentido, o propósito, as causas, efeitos e prováveis resultados desse processo, o mesmo ficará desacreditado e desconexo daquilo o que pretendia. O objetivo de uma inovação não é somente criar valor, mas fazer com que este valor seja percebido na mesma proporcionalidade enquanto resultado do que quando foi concebido. É fazer com que se acredite na potencialidade da mesma. Este aspecto está intrinsecamente associado com as bases das inovações sociais quando falamos das mudanças sociais, de comportamentos, atitudes, discursos e, sobremaneira, das visões de mundo ao passo em que a inovação social é empreendida. Ao mesmo tempo em que se tem a interpretação, tem-se as capacidades, uma vez que os processos não caminham "sozinhos" e as pessoas precisam estar capacitadas para executar metodologias, técnicas, ações, projetos etc., coordenadamente no alcance de objetivos em comum a todos.

Entendemos que as ferramentas e processos devem ser percebidos de forma orgânica, em que diversos atores participem na construção em bases abertas e colaborativas, com reconhecimento e identificação. Não se trata de um procedimento utópico a ser empreendido dentro das organizações, mas uma forma alternativa aos processos fechados e replicados por sobre as pessoas, sem critérios e desordenamente, ainda que com um pretenso "planejamento" das atividades associadas com os objetivos.

Este processo abre margens às bases para aprendizagem e formação de capacitação tecnológica nas empresas. Stal (2007, p. 47) compreende que a "capacitação tecnológica significa obter capacidade de inovar, por intermédio principalmente do domínio das tecnologias em uso", sendo o "estágio prévio e necessário para a ocorrência da inovação".

Orlikowski (2007, 2009), entende que grande parte da literatura de estudos organizacionais desconsidera ou ignora a materialidade cotidiana da organização. Tal aspecto não considera a sociomaterialidade constitutiva das organizações, moldando os contornos e possibilidades do arranjo cotidiano. Para a autora, na medida em que a literatura de gestão continua a ignorar as maneiras em que a organização está criticamente ligada a formas materiais e espaços, nossa compreensão da vida organizacional permanecerá limitada na melhor das hipóteses, e enganosa na pior das hipóteses, por não considerar relacionamentos, tendências e efeitos que se estendem amplamente e se mantêm em tecnologias e contextos.

Interessante notar como neste ponto Orlikowski $(2007,2009)$ procura desconstruir as formas de compreensão da tecnologia em âmbito organizacional como black boxes, ou seja, evitar considerar esta noção. Ideias, teorias, processos, visões de mundo, práticas discursivas e não discursivas, necessidades, expectativas, esperanças e desejos são elementos humanos e sociais que fazem parte no processo de elaboração, apreensão, compreensão e difusão de aspectos que envolvem tecnologia e inovação em contextos organizacionais. Como percebido desde o início deste texto, Tecnologia não é um processo a ser considerado isoladamente, porém histórica e socialmente. A organização não é uma ilha isolada e não deve interpretar a inovação como um processo e sistema fechado. Pelo contrário, deve-se interpretá-la de forma que se entenda e mesma como um processo socialmente construído e que depende de sinergia e compreensão mútua para trazer benefícios e alcançar resultados esperados. Neste ponto, o sentido da Adequação sociotécnica proposto por Dagnino, Brandão e Novaes (2004) pode trazer alguns insights.

\section{A ADEQUAÇÃO SOCIOTÉCNICA}

Para dar conta da inovação social inicialmente proposta e solidificar o marco analíticoconceitual da TS, Dagnino, Brandão e Novaes trazem a abordagem sociotécnica via o processo de construção sociotécnica tem como principal conceito a "Adequação Sociotécnica".

Perspectivas em Gestão \& Conhecimento, João Pessoa, v. 9, n. 1, p. 4-23, jan./abr. 2019. 
O argumento central é de que a "tecnologia é socialmente construída por 'grupos sociais relevantes' no âmbito do 'tecido sem costuras' da sociedade". Vê-se este processo não como atomizado, mas amplo e que possui interconexões. Os atores atuam na forma de atorrede, atores "que se relacionam de modo diverso", durante um longo período de tempo, sendo os responsáveis pela transformação (via incorporação, exclusão ou redefinição; além da reorientação das relações) ou consolidação da rede por eles formadas. A própria estrutura dos artefatos criados pela rede conformaria a rede, além de proporcionar plataforma para outras atividades, por ser uma compreensão sistêmica e não uniforme linear. Os interesses, as negociações, as controvérsias, as estratégias associadas aos elementos humanos, mas também dos aspectos relativos aos demais elementos não-humanos "seria o ponto de partida para entender a dinâmica de uma sociedade em que as considerações sociológicas e técnicas estariam inextricavelmente ligadas" (DAGNINO, BRANDÃO, NOVAES, 2004, p. 37).

Os interesses e disputas estão presentes nas tecnologias e na Ciência. O processo não é neutro, acadêmica e cientificamente protegido contra qualquer interesse externo ou interno à própria instituição em que é desenvolvido. Pelo contrário; o processo evolui em paralelo ao contexto em que está situado e pelos atores - ao mesmo tempo em que é incentivado reciprocamente.

As tecnologias seriam construídas socialmente "na medida em que os grupos de consumidores, os interesses políticos e outros similares influenciam não apenas a forma final que toma a tecnologia, mas seu conteúdo" (DAGNINO, BRANDÃO, NOVAES, 2004, p. 38). 0 determinismo não está mais presente como verdade inabalável frente às tecnologias e teorias. Ideias, propostas, e problemas são influenciados de tal forma dinâmica com a presença de valores e interesses sociais, reorganizando a forma como os mesmos são percebidos, pensados, contextualizados, discutidos e problematizados.

Como situado por Pinch \& Bijker (1986, 1984), é fundamental ter conhecimento sobre os atores relevantes "envolvidos no desenvolvimento de um artefato", justamente por ser o ponto de partida para a abordagem construtivista, por ser um objeto, uma tecnologia, uma técnica, uma metodologia etc., construída socialmente entre atores.

Aqui outro conceito é basilar: o conjunto sociotécnico. Este conceito denota "os arranjos entre elementos técnicos e sociais que dão como resultado uma outra entidade", que se transforma em um novo objeto de estudos voltado à explicação da condição tecnológica da mudança social e da condição social da mudança tecnológica (DAGNINO, BRANDÃO, NOVAES, 2004).

Isso traz duas implicações: a primeira, ao relacionar o ambiente social com o projeto de artefato, onde há significação de um marco aceito pelos grupos sociais entrelaçados na própria construção do mesmo, que acaba por guiar sua trajetória de desenvolvimento. Isso aponta uma ideia comum partilhada que organiza os atores no empreendimento e que posteriormente é desenvolvido.

A segunda implicação está no fato de explicar a influência do ambiente social no projeto de um artefato e como a tecnologia existente influencia o ambiente social. Como já situado, a tecnologia não é neutra; nem o objeto ou artefato derivado dela também tem neutralidade. Pelo contrário, as condições sociais, materiais, econômicas, políticas, institucionais influenciam na forma como o objeto/tecnologia é percebido e elaborado (FREITAS; SEGATTO, 2014; GARCIA, 2014). Quando posteriormente desenvolvido, esse mesmo objeto ou tecnologia é capaz de transformar o ambiente, justamente pelo fato de ter sido criado ou desenvolvido com tal finalidade.

A mesma prerrogativa de análise do artefato pode ser transposta para análise de processos imateriais como aspectos organizacionais, arranjos governamentais, políticas públicas, ações intervencionistas estatais, por exemplo. Uma política pública é parte de um 
processo conjuntural do e no ambiente social nestas duas implicações, onde a construção social é parte do processo de legitimação e institucionalização da mesma.

A mudança do ambiente pode ser adaptativa ou transformadora. No caso das TCs ela é adaptativa, pois é realizada com pauta na neutralidade da ciência, longe das relações sociais e da problematização da realidade social. Aqui a ciência e a tecnologia não têm compromisso direto com a transformação social - cabem aos atores sociais a responsabilidade pelo tal via as inovações empreendidas.

Mas por outro lado, a mudança pode ser transformadora. E isso é o que se propõem a TS, ao trazer os atores afetados pela problemática ou que anseiam mudança no status quo para dentro da construção da tecnologia não como medida de replicação, mas como forma de potencializar um projeto voltado à realidade social local. Neste ponto, a mudança pode ser transformadora positiva ou negativa da realidade social - positiva quando se consegue trazer benefícios e eliminar aquilo o que era considerado como negativo; e negativa quando não se consegue atingir tal possibilidade.

A política pública, enquanto ação que materializa a atuação do Estado sobre a realidade social (SECCHI, 2010, RUA, 2009), é um processo que visa a mudança do status quo, seja no sentido adaptativo ou na vertente transformadora. A política pública lida com o problema público - que no sentido da Ciência Política é o lapso entre a situação atual e a situação ideal - e que pode ser "tratado" nestas duas possibilidades. Vários autores desse campo do conhecimento criaram modelos analíticos que interpretam as políticas tanto no sentido adaptativo quanto no transformador.

Em certo ponto, somente pela análise do processo de construção social é que se pode alcançar e interpretar a conjuntura que levou a se empreender uma política pública, ou à criação de um arranjo governamental, ou firmamento de associações estatais, por exemplo, cujos objetivos contenham a adaptação ou transformação da realidade social. Uma política pública não é empreendida sem algum sentido material; ela é fruto de um incômodo. Porém, tal incômodo é construído socialmente enquanto percepção da realidade. E isto impacta no tipo da possibilidade de mudança.

O processo de construção sociotécnica compreende o processo em que "artefatos tecnológicos vão tendo suas características definidas por meio de uma negociação entre grupos sociais relevantes, com preferências e interesses diferentes" (DAGNINO, BRANDÃO, NOVAES, 2004, p. 40). Esse processo, no que toca a construção em si, passaria por uma fase de "estabilização" e chegaria ao estágio de "fechamento".

O processo de estabilização é comum em qualquer processo que compreenda a agregação de diversos atores na elaboração de propostas e tomada de decisão, sendo o processo em que interesses e problemas vão sendo ajustados e construídos participativamente até se chegar às condições mínimas para a construção social.

Evidentemente que há um momento em que os ajustes são finalizados e chega-se às bases de entendimento comuns, que acaba por iniciar o processo de inovação, já com as ideias definidas. A estabilização é o estágio que indica o fim desse processo, já com a inovação social. Outro aspecto a ser considerado na análise é a forma como se deu esse entendimento comum. Se foi "comum", negociado, entendido, forçado, barganhado etc.

Por outro lado, surge um consenso entre grupos sociais relevantes a partir da multiplicidade de visões iniciais que acaba por reduzir a possibilidade de uma inovação radical. A correlação de forças e o contexto sociopolítico que envolvem os grupos e o artefato são fundamentais para entender como o mesmo será projetado e até "melhorado". Dagnino, Brandão e Novaes $(2004$, p. 41) salientam que "as maneiras diferentes como os grupos sociais interpretam e utilizam um objeto técnico", produzem, "ao longo de seu processo de construção sociotécnica, mudanças na natureza dos objetivos". Há de se ter em consideração a

Perspectivas em Gestão \& Conhecimento, João Pessoa, v. 9, n. 1, p. 4-23, jan./abr. 2019. 
influência que grupos poderosos têm para impor uma visão dominante para com um objeto e a forma como este é interpretado, elaborado, re(construído) e re(interpretado) socialmente.

A crítica ao construtivismo ocorre em semelhança à $T A$, todavia, a fim de potencializar a própria TS em si como nova forma de compreensão. O construtivismo desafia a visão dominante na dinâmica tecnológica, por situar no desenvolvimento tecnológico a questão da negociação e conflito entre grupos sociais, com alternativas visões de problemas e soluções. A lógica técnica própria à tecnologia, dá lugar ao desenho social específico que serve de unidade e escolha "de cada engrenagem ou alavanca, a configuração de cada circuito ou programa", por exemplo (DAGNINO; BRANDÃO; NOVAES, 2004, p. 42).

Sobre a visão da tecnologia, Dagnino, Brandão, Novaes (2004, p. 48) destacam quatro correntes que abordam a tecnologia em dois eixos de análise, um horizontal que abarca a tecnologia como sendo ou autônoma ou controlada pelo homem e no eixo vertical, a tecnologia como ou neutra ou condicionada por valores.

A primeira visão recai sobre o instrumentalismo, ou seja, que combina a percepção do controle humano da tecnologia e da neutralidade dos valores. É uma visão percebida como padrão, tendo como base, a ideia da tecnologia como ferramenta ou instrumento para o atendimento das necessidades humanas. A tecnologia atua a partir de qualquer perspectiva de valor, podendo ser utilizada indistintamente. Essa visão instrumental neutraliza qualquer possibilidade de se utilizar a tecnologia como base para a mudança social, uma vez que não percebe o contexto social envolvido.

A segunda visão aponta o determinismo, combinando autonomia e neutralidade. 0 avanço tecnológico é a força motriz da história. O homem não controla a tecnologia. A contrapartida é que esta molda a sociedade via eficiência e progresso. O conhecimento natural serve à humanidade. Essa visão impede a percepção da tecnologia como capaz de induzir mudanças sociais a partir das necessidades locais. Essa visão entende que as mudanças sociais ocorrem naturalmente pelo avanço tecnológico.

A terceira visão se volta ao substantivismo, quando combinadas as percepções da tecnologia como autônoma e portadora de valores. A neutralidade permanece, contudo, há também a percepção de que a tecnologia não é meramente instrumental, pois não poderia ser utilizada para diferentes propósitos de indivíduos ou sociedades que divirjam sobre o bemviver. Aqui há uma crença sobre a tecnologia como indutora de mudança e portadora de valores. Esta outra visão também impede o uso da tecnologia como indutor de mudanças sociais uma vez que possui valores evolutivos do avanço tecnológico, tal qual no determinismo.

Na última visão, a da teoria crítica, que combina as percepções da tecnologia como controlada pelo homem e condicionada por valores, reconhece as negatividades do substantivismo, mas vê a tecnologia como promessa de liberdade. Não há instituições que controlem a tecnologia. É nesta última visão que aponta para uma possibilidade de instrumentalização da TS, por meio da criação de instituições sólidas que permitam pensar a tecnologia democraticamente.

A Adequação Sociotécnica (AST) se situa no marco analítico da TS com uma demanda processual, uma visão ideológica e um elemento de operacionalidade. A AST considera a TS como um processo de construção social, em essência político, "operacionalizado nas condições dadas pelo ambiente específico onde irá ocorrer, e cuja cena final depende dessas condições e da interação passível de ser lograda entre os atores envolvidos" (DAGNINO, BRANDÃO, NOVAES, 2004, p. 51). Neste contexto, procurar reforçar o papel dos atores, da tecnologia, do ambiente e do contexto que os envolve, ou seja, possui uma posição política crítica acerca do tema.

A AST é um processo que "busca promover uma adequação do conhecimento científico e tecnológico [...] não apenas aos requisitos e finalidades de caráter técnico-

Perspectivas em Gestão \& Conhecimento, João Pessoa, v. 9, n. 1, p. 4-23, jan./abr. 2019. 
econômico, [...] mas ao conjunto de aspectos de natureza socioeconômica e ambiental que constituem a relação CTS [Ciência, Tecnologia e Sociedade]". Na otimização de suas implicações, a AST objetiva adequar a TC aplicando "critérios suplementares aos técnicoseconômicos" aos "processos de produção e circulação de bens e serviços em circuitos nãoformais situados em áreas rurais e urbanas" (DAGNINO, BRANDÃO, NOVAES, 2004, p. 52).

Como percebido, a AST se propõe à uma nova racionalidade que procure empoderar (empowerment) grupos sociais, não apenas com medidas intervencionistas, mas com a apropriação de meios concretos para superação das negatividades que enfrentam. A tecnologia aqui tem um propósito ao mesmo tempo em que possui controle pelos grupos sociais, sendo condicionada pelos valores dos mesmos no ambiente de negociação e conflito que existe em qualquer ambiente político.

Ainda neste contexto, Cajaiba-Santana (2014, p. 44) entende que no âmbito da inovação social existem três nós conceituais fundamentais para se pensar em propostas inovadoras. O primeiro nó é o de que uma resposta a um problema social não é necessariamente uma inovação social e que inovações tecnológicas às vezes podem suprir essas lacunas. Em segundo, a inovação social é manifestada em mudanças de atitudes, comportamento ou percepções, resultando em novas práticas sociais. Por fim, tecnologia e inovação social se relacionam com mudança social e esta é a principal característica a ser enfatizada no seu desenvolvimento.

Cajaiba-Santana (2014) argumenta que a literatura sobre tecnologias e novações com foco no social é fragmentada, desconexa e dividida entre diferentes campos, além de a maioria se aterem a estudos de caso, por exemplo, sobre desenvolvimento urbano e regional, políticas públicas, psicologia social e empreendedorismo social. Hulgard e Ferrarini (2010) corroboram tal perspectiva de que se costuma associar e por às vezes, confundir os elementos e conceitos que envolvem a Inovação Social e o Empreendedorismo Social. Os próprios autores desenvolvem seus argumentos na perspectiva da interpretação conjunta, uma vez que "são operações que combinam criação de valor social e mudança social” (2010, p. 257).

Por conta disso é que Cajaiba-Santana (2014) pondera que não necessariamente as novas práticas sociais terão os mesmos impactos nos diferentes atores e grupos envolvidos/interessados. Por isso que nem todo processo de mudança social é necessariamente uma inovação social, como destaca Cajaiba-Santana (2014, p. 44), "as inovações socias estão associadas com ações objetivas intencionadas, planejadas, coordenadas, e legitimadas assumidas por agentes sociais tendo como meta a mudança social que surgirá no estabelecimento de novas práticas sociais". Mas o estabelecimento de novas práticas deve ser um desejo que oriente as ações, até pelo fato de que existe uma construção social sobre o que seria "socialmente desejável" no processo de engajamento social e cooperação por entre diferentes grupos sociais.

As inovações sociais têm como saídas novas Instituições, novos movimentos sociais, novas práticas sociais, ou diferentes estruturas de trabalho colaborativo que têm um impacto no desenvolvimento social futuro e na presente estabilidade além dos "modismos" temporários (CAJAIBA-SANTANA, 2014, p. 45). A perspectiva integradora de Cajaiba-Santana vem a aprofundar esse contexto em que se analisa como as ações dos agentes estão relacionadas às estruturas da sociedade e como as Instituições podem, paralelamente, permitir e/ou restringir o aparecimento das inovações sociais. Tal prerrogativa é pela perspectiva de que as inovações sociais ocorrem com orientação frente às práticas sociais, no sentido de que elas são contextuais, mas que também sofrem pressão de diferentes atores.

A inovação social envolve trocas de conhecimentos e saberes, em torno de processos que mudem práticas sociais, visões de mundo, comportamentos mas, sobretudo, que mudem a correlação de forças e possibilitem mudanças sociais de fato, com novas conjunturas sociais que privilegiem o protagonismo social em que diferentes atores e grupos sociais sejam

Perspectivas em Gestão \& Conhecimento, João Pessoa, v. 9, n. 1, p. 4-23, jan./abr. 2019. 
visibilizados e participem ativamente de processos não somente no âmbito público da tomada de decisão, mas também em processos autônomos internos e externos. As inovações sociais não veem somente o resultado, mas também o processo, para que não empreenda ações que pouco alteram o status quo, mantendo velhas forças no exercício do poder de forma hegemônica. As inovações sociais precisam ser "sociais" por excelência, agregando diferentes atores e grupos em processos abertos, participativos e colaborativos que privilegiem a Participação, o Reconhecimento e a Colaboração como valores intrínsecos em si, compartilhados por entre si e que norteiem todo o processo inovativo que envolve a conjuntura.

\section{CONSIDERAÇÕES FINAIS}

A Tecnologia Social pressupõe a necessidade do desenvolvimento local em bases igualitárias, observando as características locais e a apropriação das tecnologias pela comunidade, transformando-os de usuários a agentes transformadores da realidade. Aqui, as bases da Tecnologia Social vão ao encontro dos pressupostos da Economia Solidária, que só pode ser empreendida sob bases igualitárias pelos que se associam para produzir, comerciar ou poupar, o que Paul Singer (2002) denomina associação entre iguais em vez do contrato entre desiguais.

E é aqui que a tecnologia tem papel fundamental: a emancipação dos atores envolvidos na construção do que Tenório $(1998$, p. 19) destaca como cidadania deliberativa, por meio da qual "a pessoa toma consciência da sua função como sujeito social, e não adjunto, e como tal passa a ter uma presença ativa e solidaria nos destinos de sua comunidade". Rodrigues e Barbieri consideram a cidadania deliberativa como "aspecto central da dimensão política desse novo modo de conceber o desenvolvimento (RODRIGUES, BARBIERI, 2008, p. 1083).

Ou seja, a Tecnologia Social procura bases interdependentes que se pautam pela emancipação dos atores sociais e pela tentativa de superação do modelo capitalista de produção e consumo. É uma alternativa que surge das próprias incongruências que o sistema capitalista fornece: das suas fraquezas nascem os questionamentos e a necessidade de uma outra economia, menos agressiva e mais associativa.

O processo democrático na tomada de decisão passa a ser fator determinante, como de todo o processo que envolve a Tecnologia Social, uma vez que o uso e a replicação desta última "são endereçados à população e aos atores envolvidos", procurando eliminar "a possibilidade de apropriação privada dos conhecimentos por meio de direitos de propriedade industrial [...], pois a novidade que a solução vier a trazer passa a ser conhecida e de domínio público, uma condição necessária para viabilizar a sua replicação" (RODRIGUES, BARBIERI, 2008, p. 1083).

Não é uma questão de se "bater de frente" com o Capitalismo. Até porque se empreendimentos solidários fossem competir nessa intencionalidade, padeceriam - como padecem, em pouco tempo. A proposta também não é a de convivência "harmônica", também pelo sentido de que nunca é um processo harmônico, já que o capitalismo necessita de uma pobreza e miséria "reguladas" até o ponto de se ter mercado em que se tenha mão-de-obra barata que possa consumir no "mercado dos pobres". Barbieri e Rodrigues (2008, p. 1080) destacam que a presença desse movimento no cenário econômico "não é efêmera e os empreendimentos não só geram benefícios sociais, mas ganhos reais em eficiência e, por conseguinte, condições de assegurarem sua própria reprodução" e que "podem ser objetos de políticas públicas".

A Tecnologia Social enquanto proposta de desenvolvimento no sentido político precisa considerar a historicidade de movimentos como os trilhados pela TA e AST, de tal forma que

Perspectivas em Gestão \& Conhecimento, João Pessoa, v. 9, n. 1, p. 4-23, jan./abr. 2019. 
possa construir socialmente a percepção, por entre diversos atores, de que pode ser um processo de transformação positiva da realidade social e não um mero instrumentos que mude o status quo minimamente, mas que se adapte aos novos contextos. Ao pensarmos na contribuição da Tecnologia Social para com empreendimentos solidários organizados em sistemas de arranjos governamentais, a proposta é a de considerar a mesma enquanto base para políticas de desenvolvimento socioeconômico. A TS aponta para caminhos participativos, colaborativos, organizados "de baixo" em que se pense nas possibilidades de mudança social a partir de redes de atores organizados, cuja base é o protagonismo social de grupos e de aspectos locais.

Por isso que nem todo processo de mudança social é necessariamente uma inovação social, como destaca Cajaiba-Santana (2014, p. 44), "as inovações socias estão associadas com ações objetivas intencionadas, planejadas, coordenadas, e legitimadas assumidas por agentes sociais tendo como meta a mudança social que surgirá no estabelecimento de novas práticas sociais". Mas o estabelecimento de novas práticas deve ser um desejo que oriente as ações, até pelo fato de que existe uma construção social sobre o que seria "socialmente desejável" no processo de engajamento social e cooperação por entre diferentes grupos sociais.

Por fim, na discussão destes autores e temáticas, pretendemos construir um arcabouço mínimo para compreensão acerca dos principais itens e aspectos trabalhados no âmbito da tecnologia social, inovação e seus contextos sociais que abarcam sua materialidade. Evidenciamos a discussão da tecnologia sobretudo pelo seu aspecto de construção social que destaca seu aspecto único que não pode ser negligenciado: seu processo histórico e objetivo. Procuramos assim, constituir um texto que permitam insights para o desenvolvimento de estudos mais aprofundados em termos históricos e conceituais.

\section{REFERÊNCIAS}

ANDRADE, Thales Novaes de. Aspectos sociais e tecnológicos das atividades de inovação. Lua Nova, São Paulo, n. 66, 2006. Disponível em: http://www.scielo.br/pdf/ln/n66/29087.pdf. Acesso em: 20 dez. 2018.

ARAKAKI, Andréa Haruko et al. Sistema integrado de inovação tecnológica social: programa de incubação de empreendimentos econômicos solidários EIT-UFMT. Interações, Campo Grande, v. 13, n. 1, p. 59-68, jan./jun. 2012. Disponível em: http://www.scielo.br/pdf/inter/v13n1/a05v13n1.pdf. Acesso em: 20 dez. 2018.

BRASIL. Lei no. 10.973, de 2 de dezembro de 2004. Diário Oficial[da] República Federativa do Brasil, Brasília, DF, 2 dez. 2004. Disponível em: http://www.planalto.gov.br/ccivil 03/ ato2004-2006/2004/lei/l10.973.htm. Acesso em: 24 ago. 2013.

CAJAIBA-SANTANA, Giovany. Social innovation: Moving the field forward. A conceptual framework. Technological Forecasting and Social Change, v. 82, february, p. 42-51, 2014. Disponível em: http://www.sciencedirect.com/science/article/pii/s0040162513001236. Acesso em: 20 fev. 2015.

CARAVANTES, Geraldo R.; PANNO, Cláudia C.; KLOECKNER, Monica C. Administração: teorias e processo. São Paulo: Pearson Prentice Hall, 2005. 
DAGNINO, Renato; BRANDÃO, Flávio Cruvinel; NOVAES, Henrique Tahan. Sobre o marco analítico-conceitual da tecnologia social. In: FUNDAÇÃO BANCO DO BRASIL [FBB]. Tecnologia social: uma estratégia para o desenvolvimento. Rio de Janeiro: Fundação Banco do Brasil, 2004, p. 15-64. Disponível em: https://www.oei.es/historico/salactsi/Teconologiasocial.pdf. Acesso em: 20 dez. 2018.

DAGNINO, Renato. Tecnologia Social: contribuições conceituais e metodológicas. Paraíba: EDUEPB, 2014. Disponível em: http://books.scielo.org/id/7hbdt. Acesso em 20 de dez. 2018.

FIGLIOLI, Aline. A organização baseada em inovação. In: PORTO, Geciane Silveira (Org.). Gestão da inovação e empreendedorismo. Rio de Janeiro: Elsevier, 2013, p. 79-104.

FREITAS, Carlos Cesar Garcia; SEGATTO, Andrea Paula. Ciência, tecnologia e sociedade pelo olhar da Tecnologia Social: um estudo a partir da Teoria Crítica da Tecnologia. Cadernos EBAPE, Rio de Janeiro, v. 12, n. 2, p. 302-320, jun., 2014 . Disponível em: http://www.scielo.br/scielo.php?script=sci arttext\&pid=S1679-

39512014000200009\&lng=en\&nrm=iso. Acesso em: 20 dez. 2018.

FUNDAÇÃO BANCO DO BRASIL [FBB]. Tecnologia social: uma estratégia para o desenvolvimento. Rio de Janeiro: Fundação Banco do Brasil, 2004. Disponível em: https://www.oei.es/historico/salactsi/Teconologiasocial.pdf. Acesso em: 20 dez. 2018.

FUNDAÇÃO BANCO DO BRASIL [FBB]. Banco de tecnologias sociais. Disponível em: http://tecnologiasocial.fbb.org.br/tecnologiasocial/principal.htm. Acesso em: 20 dez. 2018.

GARCIA, Sylvia Gemignani. A tecnologia social como alternativa para a reorientação da economia. Estudos avançados, São Paulo, v. 28, n. 82, p. 251-275, Dez. 2014. Disponível em: http://www.scielo.br/scielo.php?script=sci arttext\&pid=S0103-

40142014000300015\&lng=en\&nrm=iso. Acesso em: $20 \mathrm{dez} .2018$.

GIL, Antonio Carlos. Métodos e técnicas de pesquisa social. 5. ed. São Paulo: Atlas, 2007.

HULGARD, Lars; FERRARINI, Adriane Vieira. Inovação social: rumo a uma mudança experimental na política pública? Ciências Sociais Unisinos, v. 46, n. 3, set./dez., 2010. Disponível em: http://revistas.unisinos.br/index.php/ciencias sociais/article/view/691. Acesso em: 15 maio 2015.

KLEIN, Hans; KLEINMAN, Daniel Lee. The Social Construction of Technology: Structural Considerations. Science, Technology, \& Human Values, v. 27, n. 1, Winter, 2002, p. 28-52. Disponível em: https://www.jstor.org/stable/690274. Acesso em: 20 dez. 2018.

LATOUR, Bruno. Ciência em ação. Trad. Ivone Benedetti. São Paulo: Editora da Unesp, 2000.

MACIEL, Ana Lúcia Suárez; FERNANDES, Rosa Maria Castilhos. Tecnologias sociais: interface com as políticas públicas e o Serviço Social. Serviço Social \& Sociedade, São Paulo, n. 105, p. 146-165, jan./mar. 2011. Disponível em: http://www.scielo.br/pdf/sssoc/n105/09.pdf. Acesso em 20 dez. 2018.

MACIEL, Maria Lúcia. O milagre italiano: caos, crise e criatividade. Brasília: Paralelo 15, 1996. 
MOREIRA, Daniel Augusto; QUEIROZ, Ana Carolina S. Inovação: Conceitos fundamentais. In: MOREIRA, Daniel Augusto; QUEIROZ, Ana Carolina S. [Coords]. Inovação Organizacional e Tecnológica. São Paulo: Thomson Learning, 2007, p. 1-22

NOVAES, Henrique Tahan. 0 fetiche da tecnologia: a experiência das fábricas recuperadas. 2. Ed. São Paulo: Expressão Popular, 2010.

OLIVEIRA, João Paulo Leonardo. Oportunidades para inovação. In: PORTO, Geciane Silveira [Org.]. Gestão da inovação e empreendedorismo. Rio de Janeiro: Elsevier, 2013, p. 15-28

ORLIKOWSKI, Wanda J. The sociomateriality of organisational life: considering technology in management research. Cambridge Journal of Economics, v. 34, p.125-141, 2009. Disponível em: http://dx.doi.org/10.1093/cje/bep058. Acesso em: 20 dez. 2018.

ORLIKOWSKI, Wanda J. Sociomaterial Practices: Exploring Technology at Work. Organization Studies, v. 28, n. 9, 2007, p. 1435-1448.

PINCH, Trevor; BIJKER, Wiebe. The Social Construction of Facts and Artefacts: Or How the Sociology of Science and the Sociology of Technology Might Benefit Each Other. Social Studies of Science, v. 14, n. 3, p. 399-441, aug. 1984.

PINCH, Trevor; BIJKER, Wiebe. Science, Relativism, and the New Sociology of Technology: Reply to Russel. Social Studies of Science, v. 16, p. 347-60, 1986,

PORTO, Geciane Silveira (Org.). Gestão da inovação e empreendedorismo. Rio de Janeiro: Elsevier, 2013.

RICHARDSON et al. Pesquisa social: métodos e técnicas. 3. ed. rev. ampliada. São Paulo: Atlas, 2007

RUA, Maria das Graças. Políticas públicas. CAPES: UAB, 2009.

SECCHI, Leonardo. Políticas Públicas: conceitos, esquemas de análise e casos práticos. São Paulo: Cengage Learning, 2010.

SERAFIM, Milena. DIAS; Rafael. Construção Social da Tecnologia e análise de Política: estabelecendo um diálogo entre duas abordagens. Redes, v. 16, n. 31, p. 61-73, dez., 2010.

STAL, Eva. Inovação Tecnológica, Sistemas Nacionais de Inovação e Estímulos Governamentais à Inovação. In: MOREIRA, Daniel Augusto; QUEIROZ, Ana Carolina S. (Coords). Inovação Organizacional e Tecnológica. São Paulo: Thomson Learning, 2007, p. 24-53.

SINGER, Paul. Introdução à economia solidária. São Paulo: Fundação Perseu Ábramo, 2002.

TENÓRIO, Fernando G. Gestão social: uma perspectiva conceitual. Revista de Administração Pública, Rio de Janeiro, v. 32, n. 5, p. 7-23, set./out. 1998.

WINNER, Langdon. Upon Opening the Black Box and Finding It Empty: Social Constructivism and the Philosophy of Technology. Science, Technology, \& Human Values, v. 18, n. 3, p. 362- 
378, Summer, 1993. Disponível em: https://www.jstor.org/stable/689726. Acesso em: 20 dez. 2018.

Artigo recebido em 25/05/2018 e aceito para publicação em 10/01/2019 